\title{
Research Relating to Low Back Pain and Physical Activity Reported Over the Period of 2000-2020
}

\author{
Wangwang Yan $\mathbb{D}^{1,2, *}$ \\ Yanling Yu (D) ${ }^{1,2, *}$ \\ Yafei Wang ${ }^{\prime}$ \\ Xue Jiang ${ }^{1,2}$ \\ Ruihan Wan ${ }^{1,3}$ \\ Chang Ji ${ }^{1,4}$ \\ Le Shi ${ }^{1}$ \\ Xueqiang Wang $\mathbb{( D}^{2}$ \\ Yuling Wang (D)

\begin{abstract}
'Department of Rehabilitation Medicine, The Sixth Affiliated Hospital, Sun Yat-sen University, Guangzhou City, Guangdong Province, People's Republic of China; ${ }^{2}$ Department of Sport Rehabilitation, Shanghai University of Sport, Shanghai, People's Republic of China; ${ }^{3}$ Department of Sport Rehabilitation, Shenyang Sport University, Shenyang City, Liaoning Province, People's Republic of China; ${ }^{4}$ Postgraduate Research Institute, Guangzhou Sport University, Guangzhou City, Guangdong Province, People's Republic of China

*These authors contributed equally to this work
\end{abstract}

Background: Low back pain (LBP) is a highly prevalent musculoskeletal disorder that contributes to the greatest degree of disability worldwide. It has become a very serious public health problem that has attracted considerable research interest. The number of publications associated with LBP and physical activity (PA) is gradually increasing. Nevertheless, few studies have utilised visualisation in analysing the general aspects of this field. Therefore, we aimed to provide a systematic overview of global scientific research related to low back pain and physical activity from 2000 to 2020 . It has significant benefits in terms of providing researchers with the status and trends of research on low back pain and physical activity.

Methods: Publications on Science Citation Index-Expanded of Web of Science from 2000 to 2020 were searched, and publications relevant to LBP and PA were analysed using Citespace and SPSS. Analyses mainly included cooperation amongst authors, countries and institutions; co-occurrence analysis of keywords; and co-citation analysis of references, revealing productive researchers and contributing institutions tracking the status and trend of research fields.

Results: Results of linear regression analysis showed that the number of publications on LBP and PA studies increased significantly $(p<0.001)$. The subject categories predominantly focused on orthopaedics $(2579,26.54 \%)$, rehabilitation $(2544,26.18 \%)$ and sport sciences $(2015,25.44 \%)$. The United States had the highest number of published papers $(2700,27.789 \%)$ and citations $(86,958)$. In terms of the number of publications, amongst the top 20 journals, Spine contributed the most, whilst the British Journal of Sports Medicine had the highest impact factor $\left(\mathrm{IF}_{2019}, 12.022\right)$. The University of Sydney had the highest number of publications (330 publications). Maher published the most papers (123 papers) and had the highest H-index (41). Several citation articles and keywords (such as aerobic, obesity and fear-avoidance beliefs) can be used to provide frontier clues for research on LBP and PA.

Conclusion: The results of our study may provide information, such as research trends and frontiers of research and collaborating partners, institutions and countries, on LBP and PA.

Keywords: low back pain, physical activity, research trends, Web of Science

\section{Introduction}

The definition of low back pain (LBP) depends on the location of the pain, and the pain is typically located in the lower costal margins and hip creases. ${ }^{1}$ LBP is a musculoskeletal disorder that contributes to the greatest degree of disability worldwide. ${ }^{2,3}$ About $84 \%$ of individuals are expected to suffer from LBP. ${ }^{4}$ LBP is a very common condition for all generations. It can be experienced by the elderly and children. ${ }^{5}$ LBP is currently one of the prime reasons for disability worldwide. 
For patients with LBP, only a minority of them are able to identify the cause of lower back pain. ${ }^{6}$ The relevant social and economic impact of LBP is similar to that of other common costly diseases, such as cardiovascular diseases, immunological diseases, cancer and mental health-related diseases. ${ }^{7}$ Individuals who suffer from low back pain may have a wide range of problems physical, psychological, physiological and so on. ${ }^{8}$ People who have previously had LBP episodes have increased risk of LBP recurrence. The majority of the population with LBP have low levels of disability, resulting in a very high societal burden. ${ }^{9}$

Physical activity (PA) can be classified as recreational and non-recreational PA (occupational, transport and household). PA is mainly related to frequency, intensity and duration. These factors play different roles in varying behaviour settings (domains). ${ }^{10}$ Observational and interventional studies proved positive effects of PA for diabetes, hypertension, cancer (especially breast and colon cancer), osteoporosis, cardiovascular disease, obesity and depression. They may also decrease and lengthen life span and morbidity for various reasons. ${ }^{11}$ The advantages of PA are significant to an individual's social, psychological and biological health. ${ }^{12,13} \mathrm{PA}$ has various correlations in different fields. ${ }^{14,15}$ For example, PA is one of the recommended methods for treating LBP. ${ }^{16}$ Nevertheless, guidelines do not mention which types and intensities of PA are needed for LBP. ${ }^{17}$ Moreover, the occurrence of LBP episodes or development of persistent LBP is associated with low-intensity PA, which may be related to poor physical condition, although independent associations remain uncertain. ${ }^{18}$ The reason for this is partially because of the poor lifestyle choices of people nowadays, such as sedentary behaviour or lack of PA. ${ }^{19,20}$

Bibliometric research is a method for quantitatively analysing a scientific movement explicitly, including the links amongst states, journals, institutions and authors; this method involves mathematical and statistical methods. ${ }^{21}$ Using this method, researchers can probe into the trends of research and understand research hotspots better. In recent years, studies on LBP and PA have increased. By presenting numerous data in the form of knowledge maps, analysing the course of development of discipline and frontier trends in this field can provide valuable information for researchers. In addition, the results can be used in future research and decision-making. ${ }^{22,23}$ Bibliometric research is broadly applied in determining trends in future scientific research and conducting quantitative analyses of published research. ${ }^{24,25}$ In the last decade, bibliometric analysis has been widely used to analyse scientific research in various fields, such as periodontology, ${ }^{26}$ medical research, ${ }^{27}$ functional near-infrared spectroscopy ${ }^{28}$ and PA research. ${ }^{29}$ Although several studies around the world have investigated LBP and PA, few have used bibliometrics.

CiteSpace V is a software based on Java, which visualises the information for bibliometric analysis. ${ }^{29}$ We conducted bibliometric research on the Web of Science Core Collection (WoSCC) using CiteSpace V (Drexel University, Philadelphia, PA, USA), which is a tool that is often used to evaluate research trends in certain fields around the world. ${ }^{31}$ This global study of LBP and PA includes the number of papers published, relationships and symbiosis between authors and countries, co-citation analysis of references and keyword-related hot spots. To resolve the lack of quantitative analysis of research on LBP and PA, the present study aimed to provide a systematic overview of global scientific research in this domain from 2000 to 2020 .

\section{Methods}

\section{Sources of Data}

All data were obtained from the Web of Science electronic databases. We searched for publications related to LBP and PA reported over the period of 2000-2020 and downloaded them from WoSCC. The retrieval strategy was as follows: TS = ("low back pain" OR "lower back pain" OR "LBP") AND ("motor activity" OR "exercise" OR "physical activity" OR "walking” OR "sport" OR "leisure-time activity" OR "recreation"). ${ }^{2,10}$ Document types and subject categories were not restricted. The data search was conducted on 10 February 2021 . To prevent any latent deviation, the data were retrieved within 1 day as the database was updated daily.

\section{Data Extraction}

The publications were extracted by two authors (Wangwang Yan and Yanling Yu). Relevant data, including the number of publications, citations, journals, references, countries, institutions and keywords, were extracted, recorded and analysed as bibliometric indicators.

\section{Analysis of Bibliometric and Statistical}

As a superior scientometric analysis tool, CiteSpace V was used to conduct statistical analyses on the literature. 
A variety of bibliometric parameters, such as publication number of journals, institutions, countries, ${ }^{30,32} \mathrm{H}$-index, ${ }^{33}$ impact factors and co-cited references, ${ }^{34,35}$ can measure prolific excellent individuals or groups, and identified possible partnerships among researchers in the field of LBP and PA. Co-citation relationships indicate keyword or reference cited frequently for a period of time. Cooccurrence burst demonstrate keyword or reference occurs frequently over a period of time. These parameters highlighted the main interest of this study field. ${ }^{35}$ These concepts can help us to identify research frontiers because they manifested researchers have considerable focus on these aspects in a certain period. ${ }^{28}$

The number of publications and the year they were published were analysed by linear regression analysis using IBM statistical package (SPSS 23.0). The time period was set as the independent variable, and the number of annual publications was set as the dependent variable to assess whether the citations significantly increased over time. The correlation between the number of publications and their impact factors (IFs) was calculated by Pearson's correlation analysis.

\section{Results}

\section{Publication Outputs}

We selected 9716 papers that met our inclusion criteria from 2000 to 2020. During this period, the general trend of publications on LBP and PA research increased from 139 in 2000 to 852 in 2020 (Figure 1A). As time passed, the number of articles related to LBP and PA showed a gradual increase. The results of linear regression analyses also suggested a marked increase of articles over time in the last 20 years or so $\left(R^{2}=0.994\right.$, $\mathrm{P}<0.001)$. The LOESS fit to the scatter plot is shown in Figure 1B.

On the whole, 9716 publications were cited 265,267 times. In general, 1015, 1872, 2747 and 3667 relative research articles were published during 2001-2005, 2006-2010, 2011-2015 and 2016-2020, respectively (Figure 2). The period from 2001 to 2005 had the most citations per paper (64.77), and that from 2006 to 2010 had the highest value of citations $(89,960)$ and h-index (127). Most documents published from 2016 to 2020 (3667) included open access papers (1832). A steady development trend was observed, and it barely increased, with the average annual publication being 465.05 .

\section{Types of Literature}

There were 12 literature types about research on LBP and PA (Table 1). A total of 7951 papers were written as article papers, accounting for $81.834 \%$ of all published papers. Amongst them, 'Murray et al, JAMA. 2013' was the most cited article, which had an IF of 45.54. The study described the health statement of the United States and made a comparison of US health outcomes in 34 Organisations for Economic Cooperation and Development countries. In this study, the statistical analysis method of epidemiological description about 187 countries identified 291 diseases and injuries, 1160 sequelae of these diseases and injuries and 67 risk factors for the Global Burden of Disease 2010 study from 1990 to $2010 .{ }^{36}$ The study found that LBP had the largest number of years living with disability in 2010 .

The second type of literature was review (12.175\%). 'Chou et al, Ann Intern Med. 2007' was the most cited article, which was published in Annals of Internal Medicine $\left(\mathrm{IF}_{2019}, 21.317\right)$. The review recommended seven suggestions in accordance with the clinical diagnosis and treatment of LBP. ${ }^{37}$

\section{Subject Categories of Web of Science}

Amongst the 9716 papers, there were 100 subject categories of LBP and PA research in Web of Science. Amongst the top 10 subject categories (Figure 3), orthopaedics was the largest category, including 2579 papers, based on the number of publications and citations (Table 2). At the same time, clinical neurology had the highest h-index (132).

\section{Distribution of Journals}

The 9716 papers on LBP and PA research were published in 742 journals. The top 20 journals are listed in Table 3 and Figure 4. These journals accounted for 38.21\% (3713) of all publications. Spain contributed the most publications (554) and had the maximum number of citations per paper (178.88). BMC Musculoskeletal Disorders had the most open access papers (292).

On the basis of the IFs, the top three journals were British Journal of Sports Medicine ( $\left.\mathrm{IF}_{2019}, 12.022\right)$, Pain $\left(\mathrm{IF}_{2019}, 5.483\right)$ and Journal of Orthopaedic Sports Physical Therapy $\left(\mathrm{IF}_{2019}, 3.839\right)$. These journals with high IFs have an important influence on research on LBP and PA. Pearson's correlation analysis showed no 


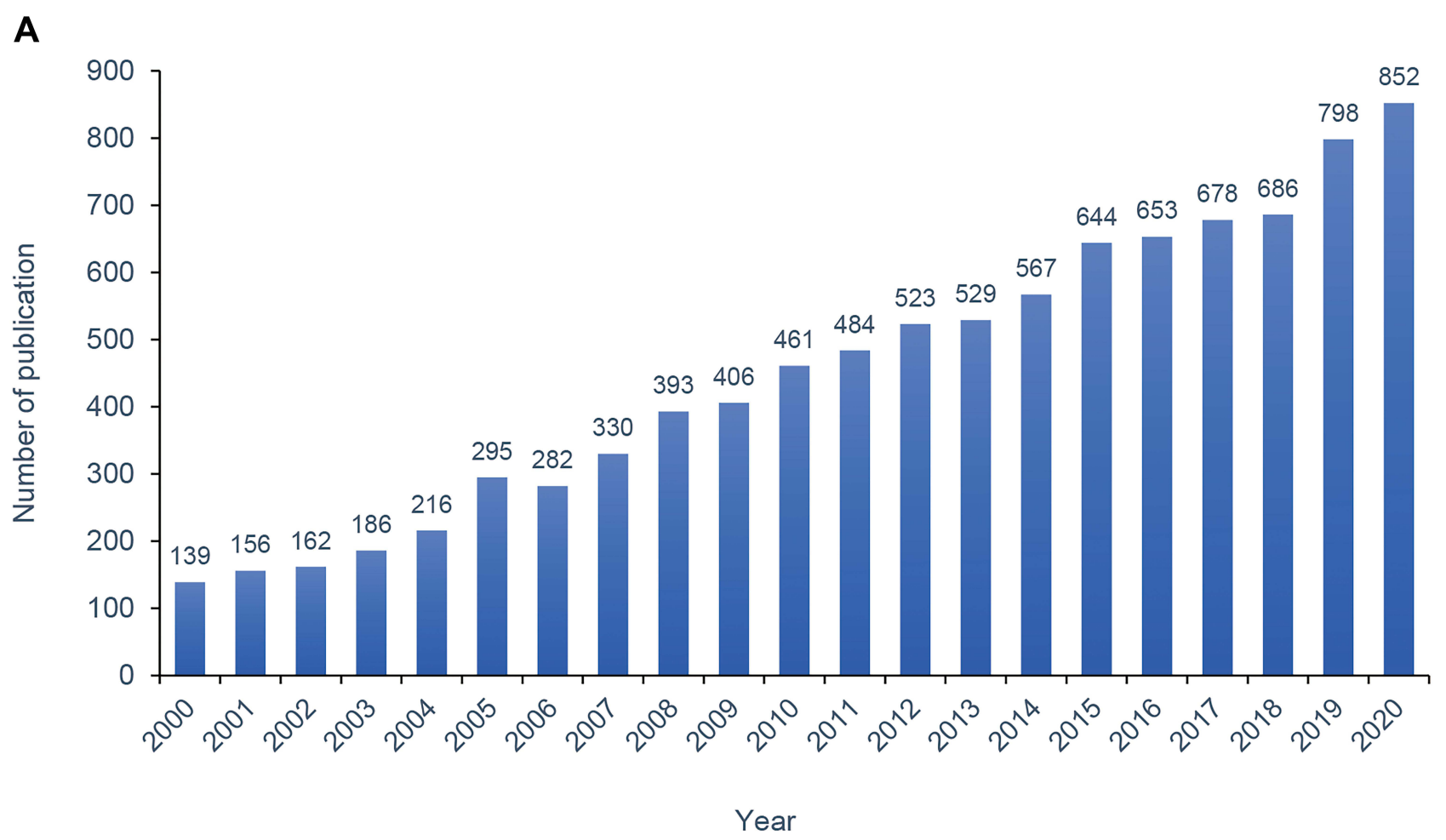

B

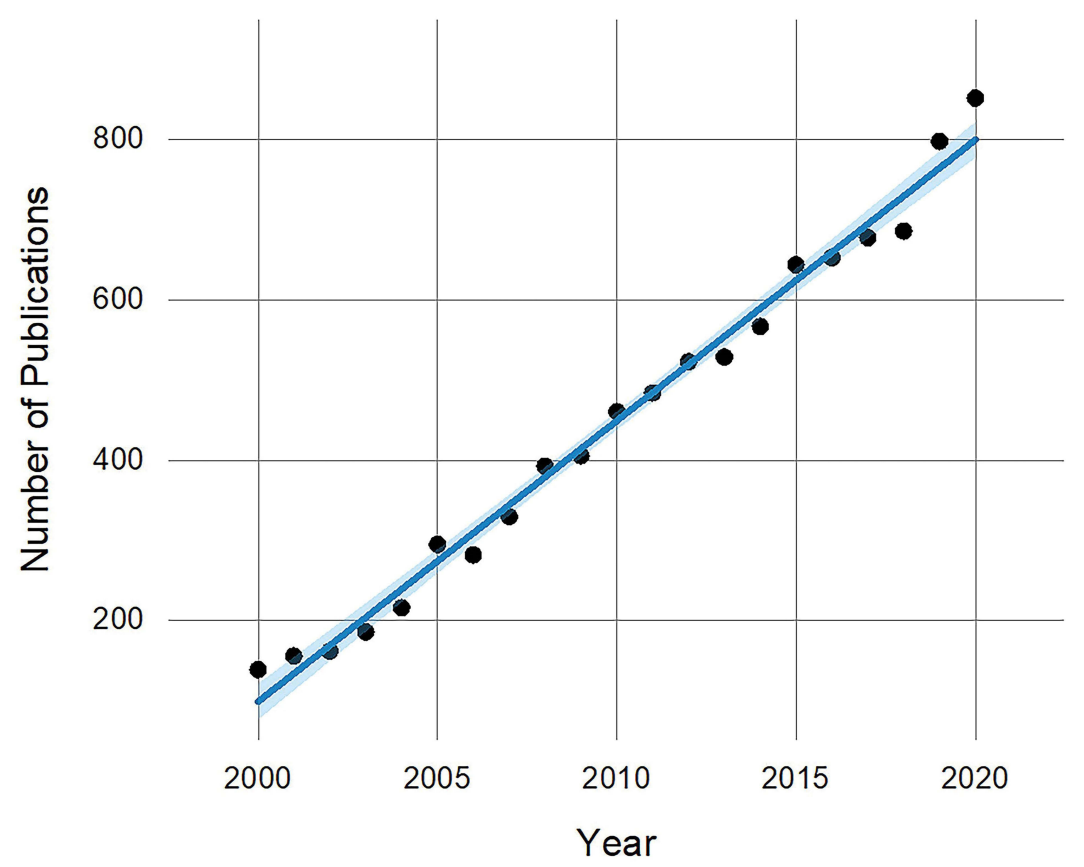

Figure I Publication outputs and time trend. (A) Output and growth trends of publications on low back pain and physical activity research from 2000 to 2020; (B) The model fitting of time trend of publications (the blue area represents the $95 \%$ confidence interval). 


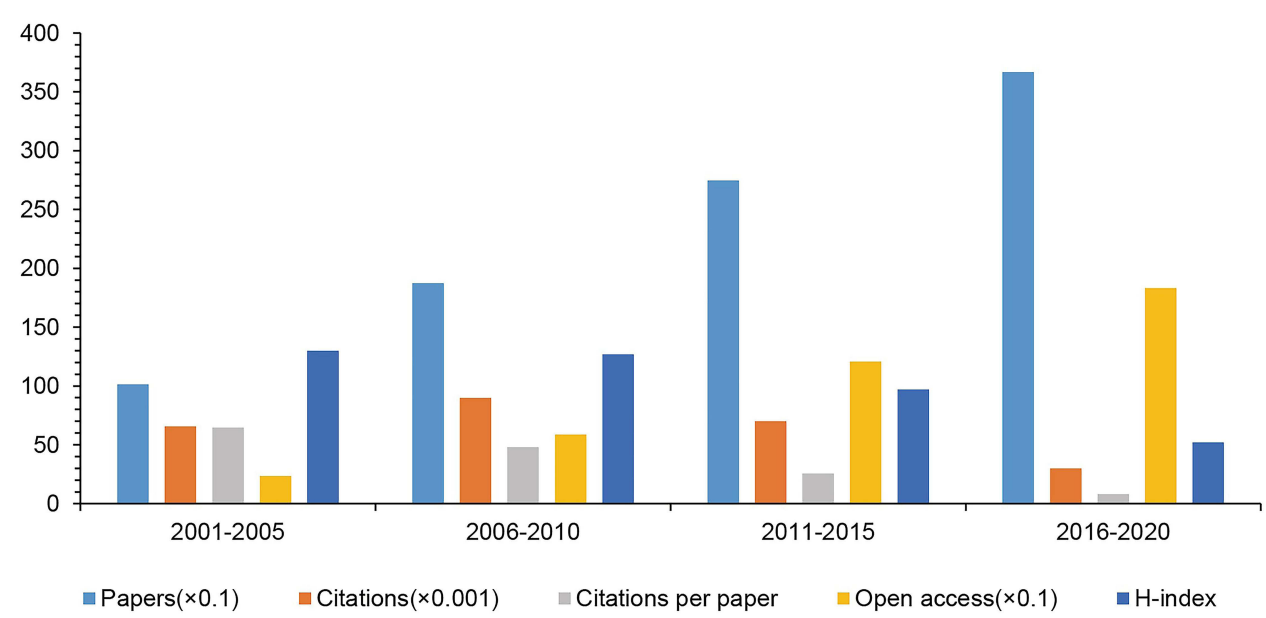

Figure 2 The number of papers, citations, citations per paper, open access papers, and $\mathrm{H}$-index of every five years.

statistical correlation between publications and IFs (r $=-0.146, P=0.529)$.

\section{Distribution of Countries and Institutions}

All articles related to LBP and PA research came from 63 countries. The United States had the maximum number of publications $(2700)$, citations $(86,958)$ and open access papers (1043), followed by Australia (1126 publications), England (888 publications) and Canada (821 publications; Table 4). Meaningful messages are provided by a co-occurrence map, which helps researchers identify cooperative relationships. ${ }^{38}$ An intimate partnership was observed between countries and territories. The top 10 countries are listed in Figure 5. The United States has close cooperative relations with Austria, England, Canada and the Netherlands.

Table I Types of Literature on Low Back Pain and Physical Activity Research from 2000 to 2020

\begin{tabular}{|l|l|l|l|}
\hline Rank & Document Type & Counts & Percentage (\%) \\
\hline 1 & Article & 7951 & $81.834 \%$ \\
2 & Review & 1183 & $12.175 \%$ \\
3 & Proceeding's paper & 158 & $1.626 \%$ \\
4 & Editorial material & 127 & $1.307 \%$ \\
5 & Meeting abstract & 71 & $0.730 \%$ \\
6 & Early access & 75 & $0.771 \%$ \\
7 & Letter & 58 & $0.597 \%$ \\
8 & Correction & 16 & $0.164 \%$ \\
9 & Reprint & 8 & $0.823 \%$ \\
10 & Book chapter & 4 & $0.412 \%$ \\
11 & News item & 3 & $0.309 \%$ \\
12 & Retracted publication & 2 & $0.206 \%$ \\
\hline
\end{tabular}

A total of 5545 institutions participated in LBP- and PA-related studies. The largest number of publications (330) was from the University of Sydney, which also had the largest number of citations $(14,716)$ and open access papers (152). In terms of citations per citation, Harvard University ranked first (86.21; Table 5). Figure 6 shows the close cooperative relationship of institutions in LBP and PA research.

\section{Distribution of Authors}

A total of 17,201 authors contributed up to 9716 papers. The top 10 high-yield authors are shown in Table 6. The network of cooperation amongst authors is shown in Figure 7. Amongst others, Maher published the most papers with 123 publications, followed by Hodges with 83 publications and Ferreira with 72 publications. Amongst the top 10 authors ranked based on citation, the most cited author was Maher (5751), who also had the highest h-index (41).

The co-citation link occurs between two elements that are referenced by the same document. Figure 7 shows several correlative authors who have an important influence in this field. For this reason, authors working in the same country or even co-authors of publications will appear in a bibliographic link.

\section{Analysis of References}

A bibliometric study consists of an analysis of references. In the analysis of the co-citation display, the distance between references demonstrates the relationship of these references in terms of co-citation. ${ }^{39}$ The most cited papers on LBP and PA research are presented 


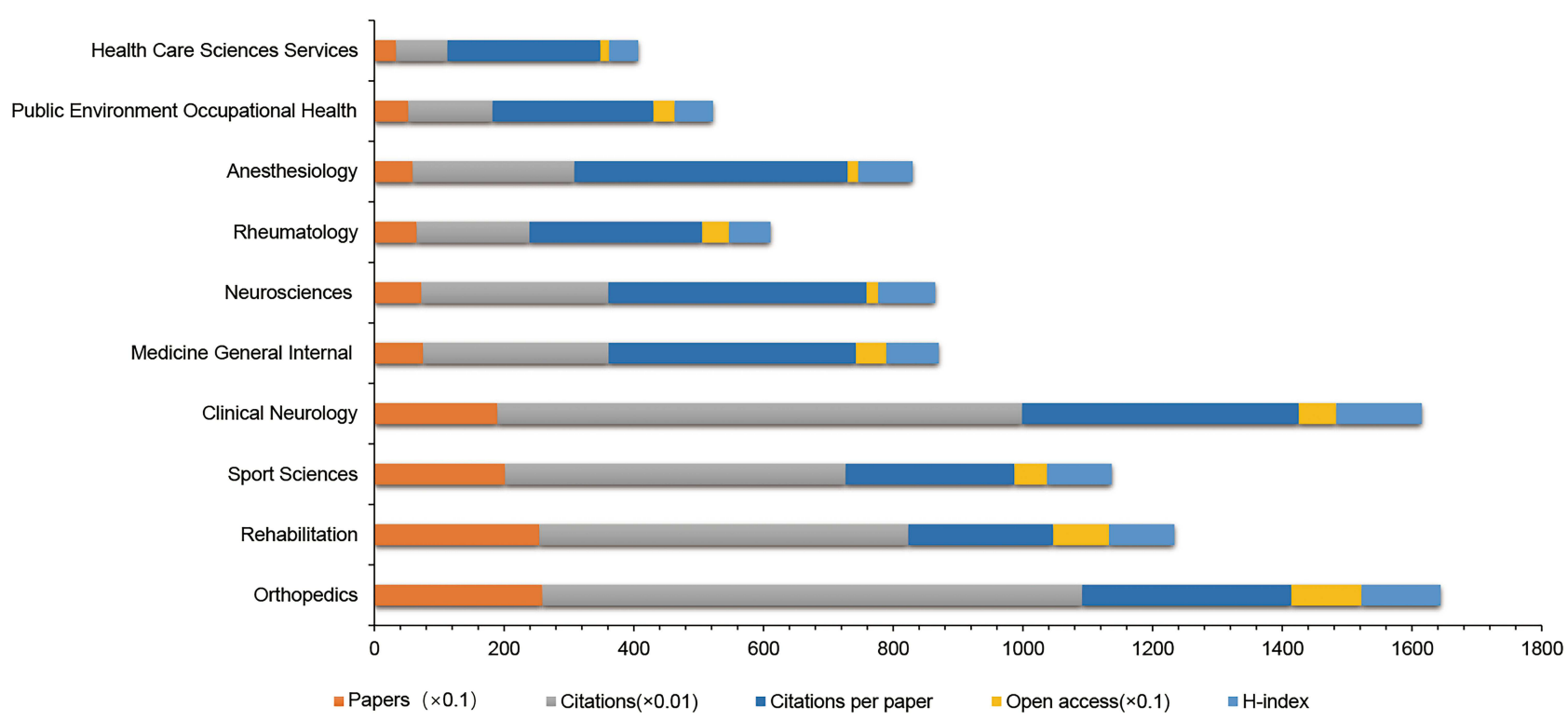

Figure 3 The number of papers, citations, citations per paper, open access papers, and $\mathrm{H}$-index of the top 10 subject categories.

in Table 7. 'Chou et al, Ann Intern Med. 2007' had the highest citations $(1746$, IF $2019=21.317)$, and its category ranking was $6 / 165$.

Amongst the top 10 papers, one was obtained in a journal with an IF $\geq 45$ (Journal of the American Medical Association, $\left.\mathrm{IF}_{2019}=45.54\right),{ }^{36}$ one in a journal with $30 \leq \mathrm{IF}<45$ (British Medical Journal), ${ }^{40}$ three from the same journal with $10 \leq \mathrm{IF}<30$ (Annals of Internal Medicine, $\left.\mathrm{IF}_{2019}=21.317\right)^{37,41,42}$ and five from journals with $1 \leq \mathrm{IF}<10$ (European Spine Journal, Scandinavian Journal of Medicine \& Science in Sports, American Journal of Industrial Medicine, Manual Therapy, Spine). ${ }^{43-47}$

The latest references with the strongest citation burst are regarded as the basic knowledge at the forefront of research. As shown in Figure 8, references that contributed to the sharp increase in citation bursts at the end of 2020 were as follows: Hoy et al (2012), Saragiotto et al (2016), Steffens et al (2016), Jordan et al (2010), Searle et al (2015), Kamper et al (2015) and Hoy et al (2014). Figure 9 shows the timeline view of the co-citation analysis of references. The clusters were named by the keyword in the cited references. The largest cluster was "aerobic" $(\# 0)$, followed by "obesity" (\#1) and "fear-avoidance beliefs' (\#2).

\section{Discussion}

The present study provides the results of bibliometric analysis about published studies on LBP and PA over the past 20 years. A total of 9716 articles were

Table 2 The Top 10 Subject Categories of Web of Science on Low Back Pain and Physical Activity Research from 2000 to 2020

\begin{tabular}{|c|c|c|c|c|c|}
\hline Rank & Subject Categories of WoS & Papers & Citations WoS & Open Access & H-Index \\
\hline 1 & Orthopaedics & 2579 & 83,237 & 1082 & 122 \\
\hline 2 & Rehabilitation & 2544 & 56,879 & 859 & 101 \\
\hline 3 & Sport Sciences & 2015 & 52,498 & 501 & 100 \\
\hline 4 & Clinical Neurology & 1896 & 80,910 & 577 & 132 \\
\hline 5 & Medicine General Internal & 75 & 28,606 & 468 & 81 \\
\hline 6 & Neurosciences & 724 & 28,827 & 18 & 88 \\
\hline 7 & Rheumatology & 652 & 17,376 & 414 & 64 \\
\hline 8 & Anaesthesiology & 591 & 24,914 & 162 & 84 \\
\hline 9 & Public Environment Occupational Health & 523 & 12,982 & 328 & 59 \\
\hline 10 & Health Care Sciences Services & 335 & 7904 & 134 & 45 \\
\hline
\end{tabular}

Abbreviation: WoS, Web of Science. 
Table 3 The Top 20 Academic Journals Published on the Association Between Low Back Pain and Physical Activity from 2000 to 2020

\begin{tabular}{|c|c|c|c|c|c|c|c|c|}
\hline Rank & Journal Title & Papers & $\begin{array}{l}\text { Citations } \\
\text { WoS }\end{array}$ & $\begin{array}{l}\text { Citations } \\
\text { per Paper }\end{array}$ & $\begin{array}{l}\text { Open } \\
\text { Access }\end{array}$ & $\begin{array}{l}\text { IF } \\
(2019)\end{array}$ & WS Categories & Quartile \\
\hline 1 & Spine & 554 & 30,865 & 55.71 & 65 & 2.646 & Clinical Neurology; Orthopedics & Q2; Q2 \\
\hline 2 & $\begin{array}{l}\text { BMC Musculoskeletal } \\
\text { Disorders }\end{array}$ & 292 & 52,229 & 178.887 & 292 & 1.879 & Orthopedics; Rheumatology & Q3; Q4 \\
\hline 3 & European Spine Journal & 262 & $12,60 \mid$ & 48.10 & 189 & 2.458 & Clinical Neurology; Orthopedics & Q3; Q2 \\
\hline 4 & $\begin{array}{l}\text { Journal of Orthopedic Sports } \\
\text { Physical Therapy }\end{array}$ & 251 & 8102 & 32.28 & 118 & 3.839 & Orthopedics; Rehabilitation; Sport Sciences & $\begin{array}{l}\text { QI; QI; } \\
\text { QI }\end{array}$ \\
\hline 5 & $\begin{array}{l}\text { Journal of Back and } \\
\text { Musculoskeletal } \\
\text { Rehabilitation }\end{array}$ & 229 & 1315 & 5.74 & 10 & 0.821 & Orthopedics; Rehabilitation & Q4; Q4 \\
\hline 6 & Manual Therapy & 190 & 8500 & 44.74 & 17 & 2.622 & Rehabilitation & QI \\
\hline 7 & Physical Therapy & 188 & 6763 & 35.97 & 172 & 3.14 & Orthopedics; Rehabilitation & QI; QI \\
\hline 8 & $\begin{array}{l}\text { Archives of Physical Medicine } \\
\text { and Rehabilitation }\end{array}$ & 173 & 6874 & 39.73 & 27 & 3.098 & Rehabilitation; Sport Sciences & QI; QI \\
\hline 9 & $\begin{array}{l}\text { Journal of Physical Therapy } \\
\text { Science }\end{array}$ & 167 & 11.98 & 7.17 & 162 & 0.392 & Rehabilitation & Q4 \\
\hline 10 & Spine Journal & 160 & 4311 & 26.94 & 36 & 3.191 & Clinical Neurology; Orthopedics & QI; QI \\
\hline 11 & $\begin{array}{l}\text { Journal of Manipulative and } \\
\text { Physiological Therapeutics }\end{array}$ & 158 & 28.48 & 18.03 & 20 & 1.23 & $\begin{array}{l}\text { Health Care Sciences \& Services; Integrative\& } \\
\text { Complementary Medicine; Rehabilitation }\end{array}$ & $\begin{array}{l}\text { Q4; Q3; } \\
\text { Q3 }\end{array}$ \\
\hline 12 & Pain & 152 & 10,952 & 72.05 & 37 & 5.483 & $\begin{array}{l}\text { Anesthesiology; Clinical Neurology; } \\
\text { Neurosciences }\end{array}$ & $\begin{array}{l}\text { QI; QI; } \\
\text { QI }\end{array}$ \\
\hline 13 & Clinical Journal of Pain & 131 & 5156 & 39.36 & 24 & 2.893 & Anesthesiology; Clinical Neurology & Q4; Q3; \\
\hline 14 & European Journal of Pain & 127 & 4296 & 33.83 & 28 & 3.492 & $\begin{array}{l}\text { Anesthesiology; Clinical Neurology; } \\
\text { Neurosciences }\end{array}$ & $\begin{array}{l}\text { Q2; Q1; } \\
\text { Q1 }\end{array}$ \\
\hline 15 & Plos One & 126 & 1685 & 13.37 & 126 & 2.74 & Multidisciplinary Sciences & Q2 \\
\hline 16 & Disability and Rehabilitation & 102 & 1432 & 14.04 & 11 & 2.222 & Rehabilitation; Rehabilitation & QI; QI \\
\hline 17 & $\begin{array}{l}\text { British Journal of Sports } \\
\text { Medicine }\end{array}$ & 98 & 38.39 & 39.17 & 46 & 12.022 & Sport Sciences & Q2; \\
\hline 18 & $\begin{array}{l}\text { Journal of Electromyography } \\
\text { and Kinesiology }\end{array}$ & 96 & 3287 & 34.24 & 9 & 1.74 & $\begin{array}{l}\text { Neurosciences; Physiology; Rehabilitation; Sport } \\
\text { Science }\end{array}$ & $\begin{array}{l}\text { Q4; Q3; } \\
\text { Q2; Q3 }\end{array}$ \\
\hline $19 *$ & BMJ Open & 86 & 376 & 4.37 & 86 & 2.496 & Medicine; General \& Internal & Q2; Q2 \\
\hline $19 *$ & Clinical Biomechanics & 86 & 2413 & 28.06 & 14 & 1.624 & Clinical; Neurology; & Q2; Q3 \\
\hline 20 & $\begin{array}{l}\text { Journal of Rehabilitation } \\
\text { Medicine }\end{array}$ & 85 & 2640 & 25.98 & 6 & 2.599 & Rehabilitation; Sport Sciences & Q2; Q2 \\
\hline
\end{tabular}

Note: *Indicates a tie for 19th place.

Abbreviations: WoS, Web of Science; IF, impact factor.

published. The most striking growth was between 2006 and 2015. All types of publications were analysed in this study, including articles (7951, 81.83\%), reviews $(1183,12.18 \%)$ and proceeding papers $(158,1.63 \%)$. Most papers were published in the form of original research papers. On the basis of the subject category of Web of Science, the fields with the largest publications were orthopaedics (2579), followed by rehabilitation (2544), sport sciences (2015) and clinical neurology (1896). 


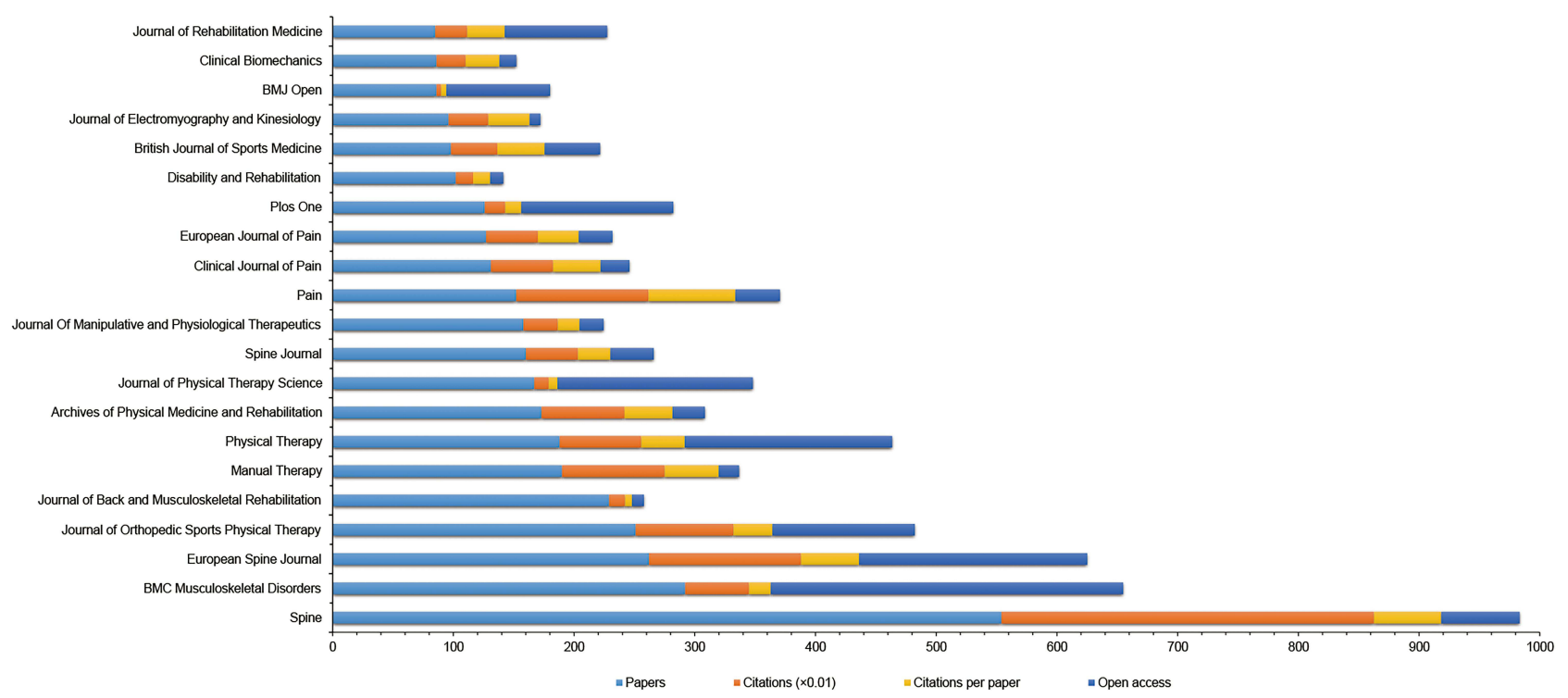

Figure 4 The number of papers, citations, citations per paper, open access papers of the top 20 journals.

In terms of the number of published papers, the top 20 journals accounted for $38.21 \%$ (3713) of all publications. The British Journal of Sports Medicine had the highest IF $\left(\mathrm{IF}_{2019}, 12.022\right)$. Publications with an IF > 3.000 accounted for $31.05 \%$ of all identified publications.

A total of 5545 institutions participated in publications related to LBP and PA. On the basis of national and institutional analyses, three institutions in the United States (University of Washington, University of Florida and Harvard University) were included in the top 10. Australia (University of Sydney and University of Queensland) and the Netherlands (Vrije Universiteit Amsterdam and Maastricht University) each had two institutions included in the top 10. The United States ranked first in terms of the number of publications (2700), followed by Australia (1126) and England (888). Five of these countries are from Europe.

We found a large number of authors who made outstanding contributions in this field. For instance, Maher published the most papers (123 publications) and had the highest h-index (41). Their research showed that patients with acute LBP and associated disability usually make a very good recovery within a few weeks, and pain and disability are usually persistent with a high recurrence rate. ${ }^{40}$ Ferreira et al (2019) indicated that the recovery from the pain attack cannot be predicted based on PA participation, and the level of PA of all subjects returns to pre-pain participation after 12 months. ${ }^{48}$

The most recently published and most frequently cited references will help us to better explore the frontiers of this research. ${ }^{39-49}$ As shown in Figure 9, references related

Table 4 The Top 10 Country of Origin of Papers on Low Back Pain and Physical Activity Research from 2000 to 2020

\begin{tabular}{|l|l|l|l|l|l|l|}
\hline Rank & Country & Papers & Percent & Citations & Citations per Paper & Open Access \\
\hline 1 & USA & 2700 & $27.78 \%$ & 86,958 & 32.21 & 1043 \\
2 & Australia & 1126 & $11.58 \%$ & 43,903 & 38.99 & 463 \\
3 & England & 888 & $9.14 \%$ & 35,766 & 40.28 & 445 \\
4 & Canada & 821 & $8.45 \%$ & 32,689 & 39.82 & 277 \\
5 & Netherlands & 653 & $6.72 \%$ & 35,739 & 54.73 & 295 \\
6 & Germany & 471 & $4.84 \%$ & 17,542 & 37.24 & 214 \\
7 & South Korea & 430 & $4.42 \%$ & 18,449 & 42.90 & 207 \\
8 & Sweden & 390 & $4.01 \%$ & 6242 & 16.01 & 219 \\
9 & Brazil & 384 & $3.95 \%$ & 9911 & 25.81 & 179 \\
10 & Denmark & 382 & $3.93 \%$ & 9352 & 24.48 & 163 \\
\hline
\end{tabular}




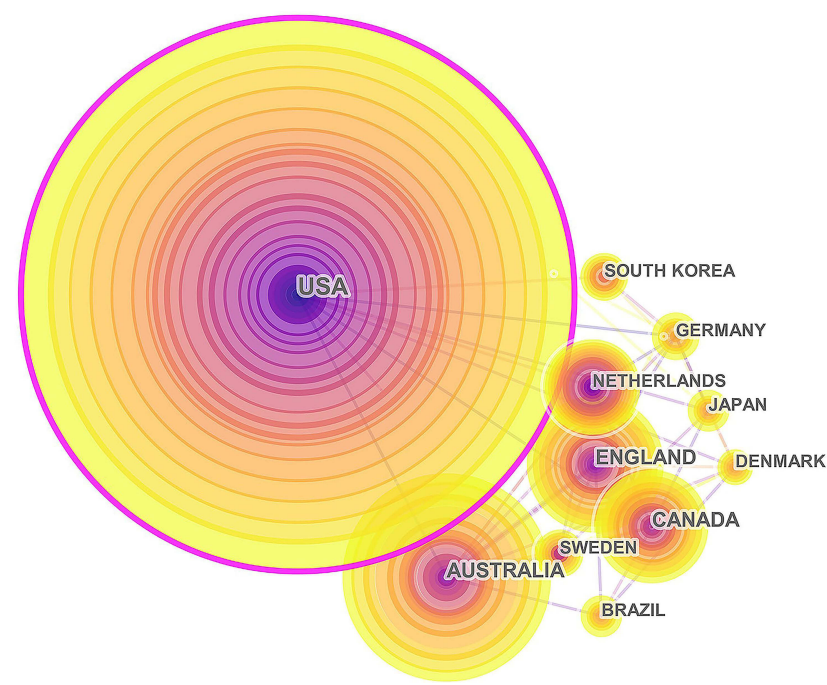

Figure $\mathbf{5}$ Network of cooperation among countries on low back pain and physical activity research from 2000 to 2020 .

to the sharp increase in citations at the end of 2020 were as follows: (1) Hoy et al (2012) systematically reviewed the global epidemic of LBP and other variables on its prevalence. They encouraged researchers to use new recommendations for a standard definition of LBP and to refer to a recently developed tool to assess the risk of bias in epidemiological studies. ${ }^{5}$ (2) Saragiotto et al (2016) showed that exercise is a moderately effective treatment for chronic LBP (CLBP), especially motor control exercise (MCE). However, evidence shows that MCE is not superior to other treatments. The exercise choice of patients with CLBP may depend on the preference of patients or therapists, the training of therapists, cost and safety. ${ }^{50}$ (3) Steffens et al (2016) studied the effectiveness of interventions to prevent LBP and suggested that exercise combined with education is effective. $^{51}$ (4) Jordan et al (2010) found that a supervised or individualised exercise scheme and

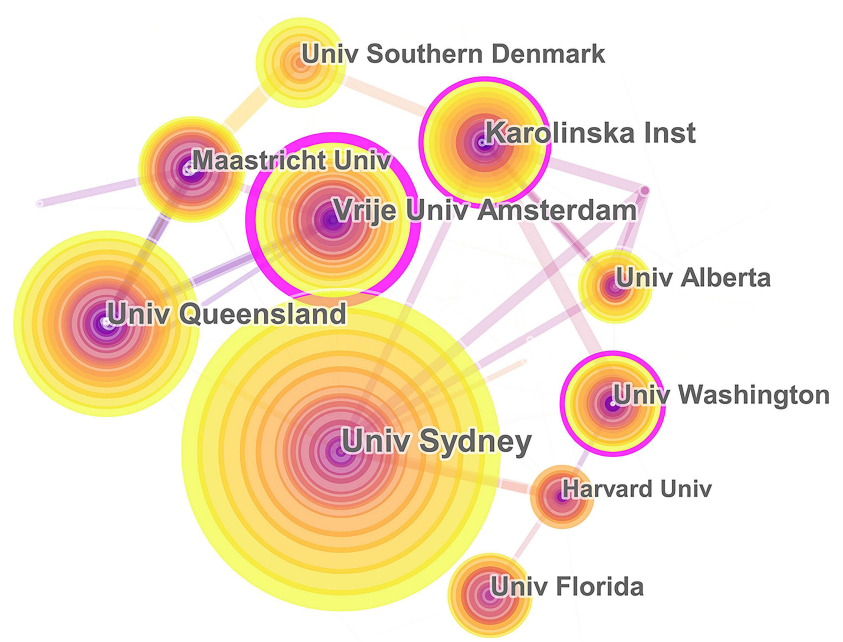

Figure 6 Network of cooperation among institutions on low back pain and physical activity research from 2000 to 2020 .

self-management can improve exercise compliance. However, the results of high-quality randomised trials requiring long-term follow-up highlight the benefits of consistent exercise and PA. In future research, standard and validated continuous motion measurement methods should be used frequently. ${ }^{52}$ (5) Searle et al (2015) reviewed published reports and found that strength/resistance training and coordination/stability training have better therapeutic effects in the treatment of CLBP compared with other types of exercise. ${ }^{53}$ (6) Kamper et al (2015) evaluated the long-term implications of multi-disciplinary biopsychosocial recovery for patients with LBP. Multidisciplinary interventions were found to be more effective than general management and physiotherapy in reducing pain and disability for CLBP. For the impact of work, multi-disciplinary recovery is more effective than physical therapy but not more effective than general management. ${ }^{54}$ (7) Hoy et al (2014) concluded that LBP is the number one

Table 5 The Top 10 Institutions of Origin of Papers on Low Back Pain and Physical Activity Research from 2000 to 2020

\begin{tabular}{|l|l|l|l|l|l|l|l|}
\hline Rank & Institutions & Countries & Papers & Percent & Citations & Citations per Paper & Open Access \\
\hline 1 & University of Sydney & Australia & 330 & $3.39 \%$ & 14,716 & 44.59 & 152 \\
2 & University of Queensland & Australia & 220 & $2.26 \%$ & 14,464 & 65.75 & 75 \\
3 & Vrije University of Amsterdam & Netherlands & 198 & $2.03 \%$ & 10,629 & 53.68 & 99 \\
4 & Karolinska institution & Sweden & 154 & $1.58 \%$ & 9389 & 60.97 & 72 \\
5 & University of Washington & USA & 141 & $1.45 \%$ & 11,048 & 78.35 & 61 \\
6 & Maastricht of University & Netherlands & 138 & $1.42 \%$ & 7444 & 53.94 & 60 \\
7 & University of Florida & USA & 123 & $1.26 \%$ & 4427 & 35.99 & 73 \\
8 & University of Alberta & Canada & 122 & $1.25 \%$ & 6178 & 50.64 & 41 \\
9 & Harvard University & USA & 115 & $1.18 \%$ & 9914 & 86.21 & 58 \\
10 & University of Southern Denmark & Denmark & 113 & $1.16 \%$ & 2159 & 19.42 & 77 \\
\hline
\end{tabular}


Table 6 The Top 10 Authors Who Published on Low Back Pain and Physical Activity Research from 2000 to 2020

\begin{tabular}{|l|l|l|l|l|}
\hline Rank & Authors & Papers & Citations & H-Index* \\
\hline 1 & Maher & 123 & $575 I$ & 41 \\
2 & Hodges & 83 & 5641 & 39 \\
3 & Ferreira PH & 72 & 2298 & 19 \\
4 & George & 72 & 3894 & 33 \\
5 & Fritz & 61 & 4989 & 34 \\
6 & Ferreira ML & 57 & 2505 & 21 \\
7 & Andersen & 54 & 938 & 18 \\
8 & Van Tulder & 54 & 4754 & 29 \\
9 & Costa Lop & 50 & 1377 & 21 \\
10 & Latimer & 47 & 2044 & 23 \\
\hline
\end{tabular}

Note: *The $\mathrm{H}$-index in this table was calculated only based on the LBP and PA papers published by the author.

cause of disability and sixth as far as overall burden amongst 291 disease burden studies in 2010. With the aging population, we urgently need to study LBP in different environments. ${ }^{3}$

Our research found that the largest cluster was "aerobic" (\#0), followed by "obesity" (\#1) and "fear-avoidance beliefs' (\#2).

\section{Aerobic}

PAs, especially aerobic exercise, are effective for LBP. However, the relationship amongst frequency, intensity, duration of aerobic exercise and LBP is unclear in the general population. A study showed that regular aerobic exercise such as walking regularly and daily Pilates has a significant relationship in reducing the risk of $\mathrm{LBP}^{55,56}$ Meanwhile, studies have shown that less frequent PA exacerbates the severity of LBP. A meta-analysis revealed that participation in PA reduces the incidence of LBP and

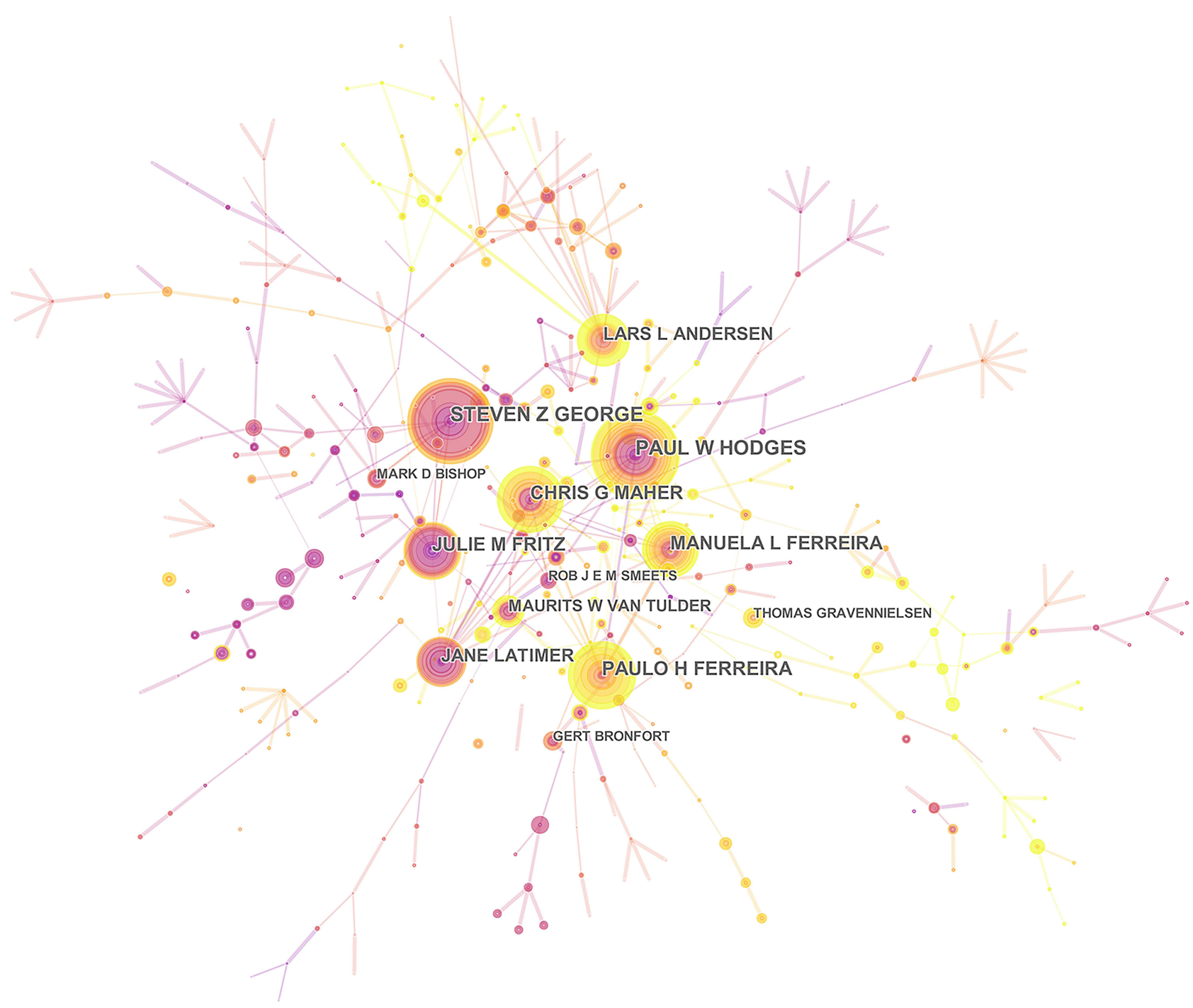

Figure 7 The top 10 authors who published on low back pain and physical activity research from 2000 to 2020. 
related disabilities, and a combination of stretching or aerobic exercises must be performed a certain number of times per week to prevent CLBP. ${ }^{57}$ As stated in a pilot study, regular high-intensity aerobic exercise reduces pain and psychological pressure in people with CLBP. ${ }^{58}$ Therefore, specific types of aerobic exercise are effective in the management of CLBP. Aerobic exercise is widely used and cost-effective for the general population. ${ }^{59}$ The American Physical Therapy Association guidelines recommend that patients with LBP but no general pain should engage in moderate- to high-intensity exercise (eg jogging and running), whilst patients with general pain should perform low-intensity or sub-maximum-intensity activities. ${ }^{60}$ Thus, in the future, we need to focus on what kind of aerobic exercise is more beneficial to LBP and propose an explanation of why and how it is better for LBP.

\section{Obesity}

Overweight and obese individuals with CLBP face several difficulties in daily life as abdominal obesity increases the occurrence of LBP. ${ }^{61}$ Continuous exercise has a positive effect on obese patients with LBP. However, how different forms of exercise are likely to play varied roles in overweight and obese patients with CLBP is unclear. For overweight and obese people, the primary health goal is to lose weight, but strength training may also maximise functional improvement for overweight and obese patients with LBP. $^{62}$ Studies indicate that the body mass index (BMI) is related to persistent LBP, and increased $\mathrm{BMI}$ is a risk factor for overweight and obese population. ${ }^{63-66}$ However, the time period during which being overweight is associated with incident LBP differs between the sexes. ${ }^{67}$ A prospective study found that BMI does not increase the occurrence of CLBP and activity limitation when genetics is considered. $^{68}$ Therefore, more attention should be paid to the relationship amongst obesity, PA and LBP.

\section{Fear-Avoidance Beliefs (FABs)}

The fear avoidance model explains why some patients with back pain develop chronic symptoms and how FABs impact PA. Pain-related fear can lead to avoidance behaviour. ${ }^{69}$ Patients with a high level of FABs think that PA can cause harm and intensify pain. FABs can better predict disability, behavioural performance and risk of $\mathrm{LBP}^{70}$ On the one hand, patients with
CLBP usually exhibit higher levels of FABs and distress than their counterparts. For the early stage of avoidance belief, better understanding and intervention are crucial. In a study on FABs and pain associated with disability in LBP, patients with acute LBP had lower level of FABs and pain compared with those with CLBP. ${ }^{71}$ Furthermore, the results indicated that FABs about PA and pain are significantly correlated with the Oswestry disability index. Moreover, FABs are generally considered one of the important risk factors for CLBP. $^{72}$ A study on the relationship between Japanese nurses' high FABs about PA and CLBP showed that targeting FABs about PA can be favourable to LBP rehabilitation. ${ }^{73}$ Whether they are patients with acute LBP, subacute LBP or CLBP, cognitive behavioural therapies and psychoeducation are often used as interventions to reduce FABs. ${ }^{74,75}$ In the near future, more interventions should be proposed to change the FABs of patients with LBP.

Overweight individuals are 1.7-2.3 times more likely to report pain compared to people of normal weight. We should first consider reducing the obese individual's weight by involving aerobic exercise, ${ }^{76}$ and then consider reducing the fear associated with the pain they will experience when performing PA. ${ }^{77,78}$ So that they achieve adherence to the exercise program and reap the benefits of long-term participation in PA. FABs are one of the important causes of LBP disability. Therefore, they can be used as a key point to control LBP. Moreover, ergonomics and psychological stress should be considered.

\section{Strengths and Limitations}

To date, no studies have performed bibliometric analysis of LBP and PA. To our knowledge, this study is the first to analyse publications in the Science Citation Index Expanded over the past 20 years. All literature categories were included in our study. Consequently, we have a wealth of data to analyse. The literature was not restricted to subject classification of a category. This study on LBP and PA research covered various kinds of academic journals, and a total of 9716 papers were published in 742 different journals. This bibliometric analysis not only covered journals, citations and publications but also included cooperation between authors and institutions.

This bibliometric study had certain restrictions. The electronic databases were limited to the Web of 
Table 7 Features of the 10 Most Frequently Cited Papers on Low Back Pain and Physical Activity Research from 2000 to 2020

\begin{tabular}{|c|c|c|c|c|c|c|c|}
\hline Rank & Title & $\begin{array}{l}\text { First } \\
\text { Author }\end{array}$ & Journal & IF & Year & Citations & $\begin{array}{l}\text { WoS } \\
\text { Categories }\end{array}$ \\
\hline 1 & $\begin{array}{l}\text { Diagnosis and treatment of low back pain: A joint } \\
\text { clinical practice guideline from the American college } \\
\text { of physicians and the American pain society }\end{array}$ & Chou & $\begin{array}{l}\text { Annals of Internal } \\
\text { Medicine }\end{array}$ & 21.317 & 2007 & 1746 & $\begin{array}{l}\text { Medicine, } \\
\text { General \& } \\
\text { Internal }\end{array}$ \\
\hline 2 & $\begin{array}{l}\text { Chapter } 4 \text { - European guidelines for the management } \\
\text { of chronic nonspecific low back pain }\end{array}$ & Airaksinen & $\begin{array}{l}\text { European Spine } \\
\text { Journal }\end{array}$ & 2.458 & 2006 & 1367 & $\begin{array}{l}\text { Clinical } \\
\text { Neurology; } \\
\text { Orthopedics }\end{array}$ \\
\hline 3 & $\begin{array}{l}\text { The state of US health, 1990-2010 burden of } \\
\text { diseases, injuries, and risk factors }\end{array}$ & Murray & $\begin{array}{l}\text { Journal of the } \\
\text { American } \\
\text { Medical } \\
\text { Association }\end{array}$ & 45.54 & 2013 & 1399 & $\begin{array}{l}\text { Medicine, } \\
\text { General \& } \\
\text { Internal }\end{array}$ \\
\hline 4 & $\begin{array}{l}\text { Exercise as medicine-evidence for prescribing } \\
\text { exercise as therapy in } 26 \text { different chronic diseases }\end{array}$ & Pedersen & $\begin{array}{l}\text { Scandinavian } \\
\text { Journal of } \\
\text { Medicine \& } \\
\text { Science in Sports }\end{array}$ & 3.255 & 2015 & 804 & Sport Sciences \\
\hline 5 & $\begin{array}{l}\text { A clinical prediction rule to identify patients with } \\
\text { low back pain most likely to benefit from spinal } \\
\text { manipulation: A validation study }\end{array}$ & Childs & $\begin{array}{l}\text { Annals of Internal } \\
\text { Medicine }\end{array}$ & 21.317 & 2004 & 540 & $\begin{array}{l}\text { Medicine, } \\
\text { General \& } \\
\text { Internal }\end{array}$ \\
\hline 6 & $\begin{array}{l}\text { Risk factors for work-related musculoskeletal } \\
\text { disorders: A systematic review of recent longitudinal } \\
\text { studies }\end{array}$ & da Costa & $\begin{array}{l}\text { American Journal } \\
\text { of Industrial } \\
\text { Medicine }\end{array}$ & 1.739 & 2010 & 514 & $\begin{array}{l}\text { Public, } \\
\text { Environmental } \\
\& \\
\text { Occupational } \\
\text { Health }\end{array}$ \\
\hline 7 & $\begin{array}{l}\text { Noninvasive treatments for acute, subacute, and } \\
\text { Chronic low back pain: A Clinical practice guideline } \\
\text { from the American College of Physicians }\end{array}$ & Qaseem & $\begin{array}{l}\text { Annals of Internal } \\
\text { Medicine }\end{array}$ & 21.317 & 2017 & 499 & $\begin{array}{l}\text { Medicine, } \\
\text { General \& } \\
\text { Internal }\end{array}$ \\
\hline 8 & $\begin{array}{l}\text { Diagnosis and classification of chronic low back pain } \\
\text { disorders: Maladaptive movement and motor } \\
\text { control impairments as underlying mechanism }\end{array}$ & O'Sullivan & Manual Therapy & $2.622 *$ & 2005 & 484 & Rehabilitation \\
\hline 9 & $\begin{array}{l}\text { Acute low back pain: systematic review of its } \\
\text { prognosis }\end{array}$ & Pengel & $\begin{array}{l}\text { British Medical } \\
\text { Journal }\end{array}$ & 30.223 & 2003 & 476 & $\begin{array}{l}\text { Medicine, } \\
\text { General \& } \\
\text { Internal }\end{array}$ \\
\hline 10 & $\begin{array}{l}\text { Clinical guidelines for the management of low back } \\
\text { pain in primary care - An international comparison }\end{array}$ & Koes & Spine & 2.646 & 2001 & 457 & $\begin{array}{l}\text { Clinical } \\
\text { Neurology; } \\
\text { Orthopedics }\end{array}$ \\
\hline
\end{tabular}

Note: *No data for 2019 were found, and the impact factor for 2018 was 2.622 .

Abbreviations: WoS, Web of Science; IF, impact factor.

Science, and other electronic databases (such as PubMed, Scopus and Embase) were not searched. Moreover, only English papers were included. In this study, a minority of the papers included were nonEnglish, thereby resulting in language bias.
In addition, some content, such as the duration, type, intensity, frequency and method of physical activity in patients with chronic low back pain, was not discussed and analyzed further here because these questions were outside the scope of this study. 


\section{References}

FERREIRA PH, 2006, AUST J PHYSIOTHER, V52, P79, DOI

LONG A, 2004, SPINE, V29, P2593, DOI

CHILDS JD, 2004, ANN INTERN MED, V141, P920, DOI

FERREIRA ML, 2007, PAIN, V131, P31, DOI

VAN TULDER M, 2006, EUR SPINE J, V15, P0, DOI

AIRAKSINEN O, 2006, EUR SPINE J, V15, PO, DOI

HAYDEN JA, 2005, ANN INTERN MED, V142, P776, DOI

FERREIRA PH, 2004, SPINE, V29, P2560, DOI

SHERMAN KJ, 2005, ANN INTERN MED, V143, P849, DOI

KOUMANTAKIS GA, 2005, PHYS THER, V85, P209, DOI

LIDDLE SD, 2004, PAIN, V107, P176, DOI

HAYDEN JA, 2005, ANN INTERN MED, V142, P765, DOI

HICKS GE, 2005, ARCH PHYS MED REHAB, V86, P1753, DOI

HAYDEN JA, 2005, COCHRANE DB SYST REV, VO, PO, DOI

CHOU R, 2007, ANN INTERN MED, V147, P478, DOI

BRENNAN GP, 2006, SPINE, V31, P623, DOI

DAGENAIS S, 2008, SPINE J, V8, P8, DOI

KOES BW, 2006, BMJ-BRIT MED J, V332, P1430, DOI

HOY D, 2012, ARTHRITIS RHEUM-US, V64, P2028, DOI

SARAGIOTTO BT, 2016, COCHRANE DB SYST REV, VO, PO, DOI STEFFENS D, 2016, JAMA INTERN MED, V176, P199, DOI

JORDAN JL, 2010, COCHRANE DB SYST REV, V0, PO, DOI

SEARLE A, 2015, CLIN REHABIL, V29, P1155, DOI

KAMPER SJ, 2014, COCHRANE DB SYST REV, VO, PO, DOI

HOY D, 2014, ANN RHEUM DIS, V73, P968, DOI

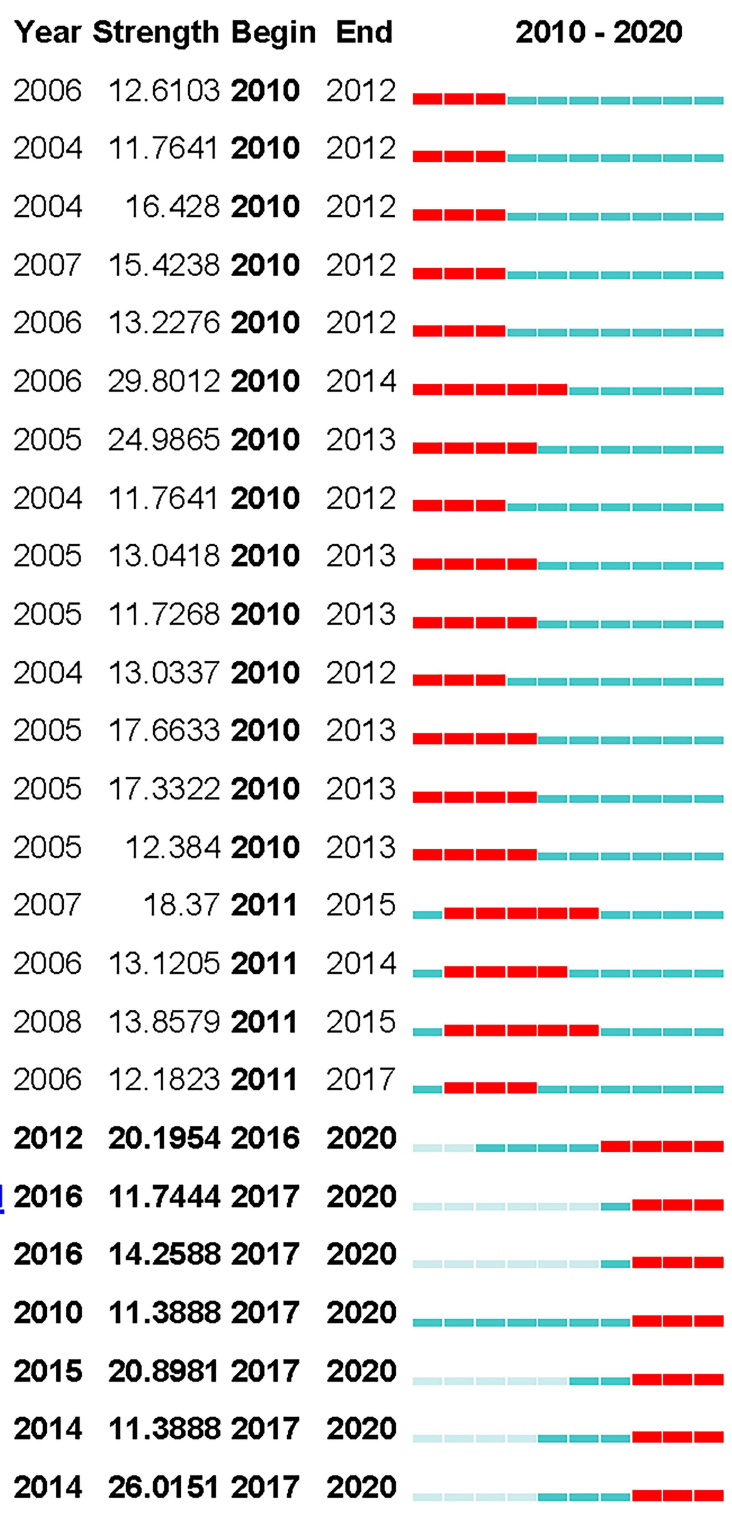

Figure 8 Top 26 references with the strongest citation bursts on low back pain and physical activity research from 2000 to 2020 .

\section{Conclusions}

This study provides global observations of the historical tendency of LBP and PA over the past two decades. The number of publications has steadily increased $(P<0.001)$. The influence of the United States was significant in terms of scientific research. The University of Sydney contributed the largest number of publications, and Maher published the most studies. In terms of the number of publications, Spine contributed the most publications, and the journal with the highest published IF in this field of research was the British Journal of Sports Medicine $\left(\mathrm{IF}_{2019}, 12.022\right)$.

Although our research presents some limitations, it adequately demonstrated the trends of LBP and PA research. The research topics of LBP and PA over the past two decades primarily focused on aerobic, obesity, and fear-avoidance beliefs. Our findings can provide effective information for LBP and PA, funding agencies and policy makers.

\section{Data Sharing Statement}

The raw data can be directly obtained from the Web of Science Core Collection (WoSCC).

\section{Acknowledgments}

This work was supported by the National Natural Science Foundation of China (No.81472155); the Guangdong 


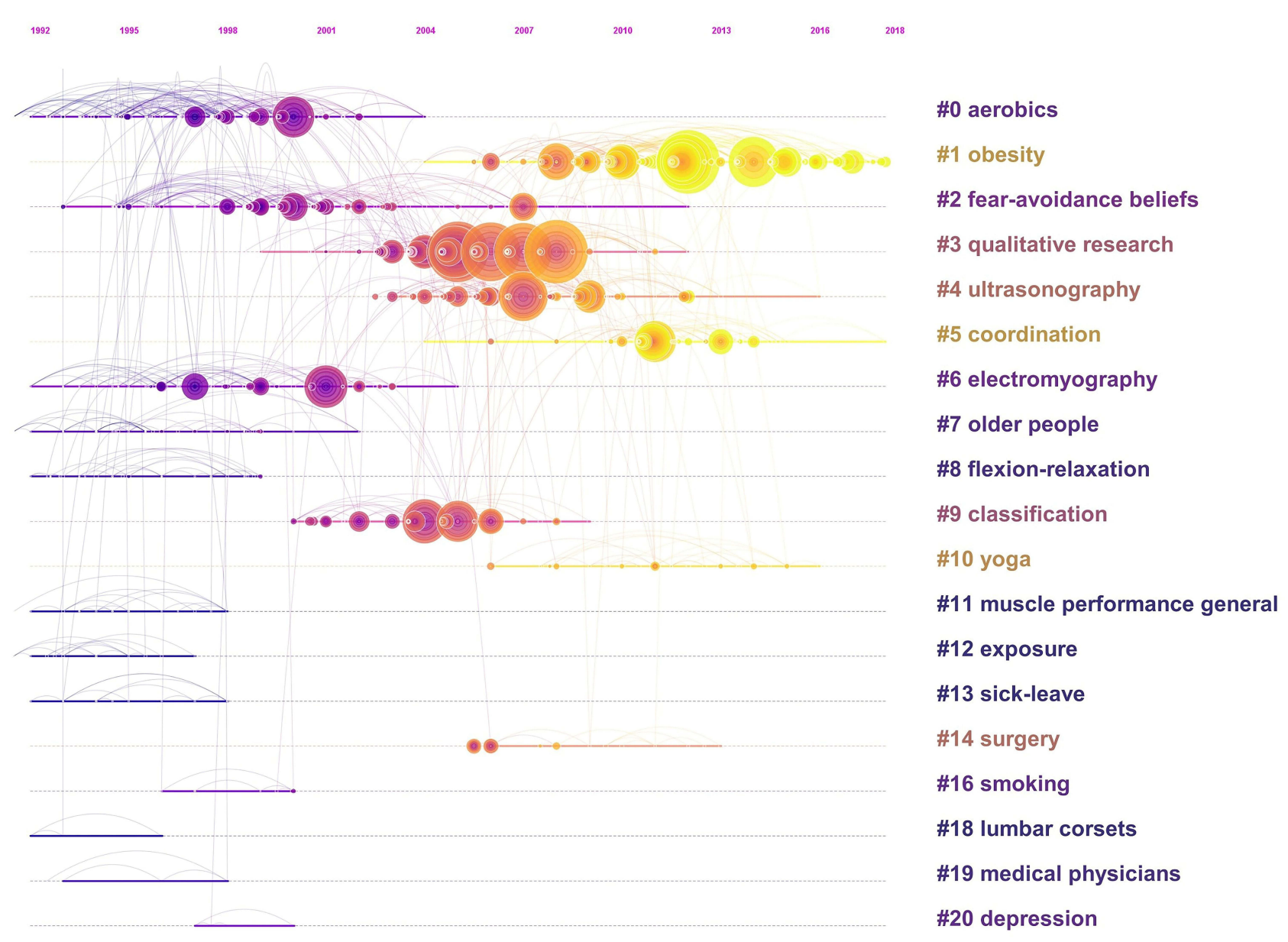

Figure 9 The timeline on low back pain and physical activity research from 2000 to 2020 .

Hopson-Pearl River Education Development Foundation (grant number H20190116202012724).

\section{Disclosure}

The authors report no conflicts of interest in this work.

\section{References}

1. Dionne CE, Dunn KM, Croft PR, et al. A consensus approach toward the standardization of back pain definitions for use in prevalence studies. Spine. 2008;33(1):95-103. doi:10.1097/BRS.0b013e31 $815 \mathrm{e} 7 \mathrm{f} 94$

2. Maher C, Underwood M, Buchbinder R. Non-specific low back pain. Lancet. $\quad 2017 ; 389(10070): 736-747 . \quad$ doi:10.1016/S0140-6736(16) 30970-9

3. Hoy D, March L, Brooks P, et al. The global burden of low back pain: estimates from the Global Burden of Disease 2010 study. Ann Rheum Dis. 2014;73(6):968-974. doi:10.1136/annrheumdis-2013-204428

4. Balagué F, Mannion AF, Pellisé F, et al. Non-specific low back pain. Lancet. 2012;379(9814):482-491. doi:10.1016/S0140-6736(11)60610-7

5. Hoy D, Bain C, Williams G, et al. A systematic review of the global prevalence of low back pain. Arthritis Rheum. 2012;64(6):2028-2037. doi:10.1002/art.34347
6. Hartvigsen J, Hancock MJ, Kongsted A, et al. What low back pain is and why we need to pay attention. Lancet. 2018;391 (10137):2356-2367. doi:10.1016/S0140-6736(18)30480-X

7. Maniadakis N, Gray A. The economic burden of back pain in the UK. Pain. 2000;84(1):95-103. doi:10.1016/S0304-3959(99)00187-6

8. Global Burden of Disease Study 2013 Collaborators. Global, regional, and national incidence, prevalence, and years lived with disability for 301 acute and chronic diseases and injuries in 188 countries, 1990-2013: a systematic analysis for the Global Burden of Disease Study 2013. Lancet. 2015;386(9995):743-800. doi:10.1016/S01406736(15)60692-4.

9. Taylor JB, Goode AP, George SZ, et al. Incidence and risk factors for first-time incident low back pain: a systematic review and meta-analysis. Spine J. 2014;14(10):2299-2319. doi:10.1016/j. spinee.2014.01.026

10. Mahmood S, MacInnis RJ, English DR, et al. Domain-specific physical activity and sedentary behaviour in relation to colon and rectal cancer risk: a systematic review and meta-analysis. Int $J$ Epidemiol. 2017;46(6):1797-1813. doi:10.1093/ije/dyx137

11. Vuori IM, Lavie CJ, Blair SN. Physical activity promotion in the health care system. Mayo Clin Proc. 2013;88(12):1446-1461. doi:10.1016/j.mayocp.2013.08.020

12. Das P, Horton R. Physical activity-time to take it seriously and regularly. Lancet. 2016;388(10051):1254-1255. doi:10.1016/S01406736(16)31070-4 
13. Arem H, Moore SC, Patel A, et al. Leisure time physical activity and mortality: a detailed pooled analysis of the dose-response relationship. JAMA Intern Med. 2015;175(6):959-967. doi:10.1001/ jamainternmed.2015.0533

14. Bauman AE, Reis RS, Sallis JF, et al. Correlates of physical activity: why are some people physically active and others not? Lancet. 2012;380(9838):258-271. doi:10.1016/S0140-6736(12)60735-1

15. Du H, Li L, Whitlock G, et al. Patterns and socio-demographic correlates of domain-specific physical activities and their associations with adiposity in the China Kadoorie Biobank study. BMC Public Health. 2014;14:826. doi:10.1186/1471-2458-14-826

16. Foster NE, Anema JR, Cherkin D, et al. Prevention and treatment of low back pain: evidence, challenges, and promising directions. Lancet. 2018;391(10137):2368-2383. doi:10.1016/S0140-6736(18) 30489-6

17. De Campos TF. Low back pain and sciatica in over 16s: assessment and management NICE Guideline [NG59]. J Physiother. 2017;63 (2):120. doi:10.1016/j.jphys.2017.02.012

18. Shiri R, Falah-Hassani K. Does leisure time physical activity protect against low back pain? Systematic review and meta-analysis of 36 prospective cohort studies. Br J Sports Med. 2017;51(19):1410-1418. doi:10.1136/bjsports-2016-097352

19. Egger GJ, Vogels N, Westerterp KR. Estimating historical changes in physical activity levels. Med J Aust. 2001;175(11-12):635-636. doi:10.5694/j.1326-5377.2001.tb143758.x

20. Woolf AD, Pfleger B. Burden of major musculoskeletal conditions. Bull World Health Organ. 2003;81(9):646-656. doi:10.1590/S004296862003000900007

21. Oelrich B, Peters R, Jung K. A bibliometric evaluation of publications in urological journals among European Union countries between 2000-2005. Eur Urol. 2007;52(4):1238-1248. doi:10.1016/ j.eururo.2007.06.050

22. Lawson McLean A. Publication trends in transcranial magnetic stimulation: a 30-year panorama. Brain Stimul. 2019;12(3):619-627. doi:10.1016/j.brs.2019.01.002

23. Ellegaard O, Wallin JA. The bibliometric analysis of scholarly production: how great is the impact? Scientometrics. 2015;105 (3):1809-1831. doi:10.1007/s11192-015-1645-z

24. Wormell I. Bibliometric navigation tools for users of subject portals. J Inf Sci. 2003;29(3):193-203. doi:10.1177/01655515030293006

25. Zyoud SH, Fuchs-Hanusch D. A bibliometric-based survey on AHP and TOPSIS techniques. Expert Syst Appl. 2017;78:158-181. doi:10.1016/j.eswa.2017.02.016

26. Ahmad P, Asif JA, Alam MK, et al. A bibliometric analysis of periodontology 2000. Periodontol 2000. 2020;82(1):286-297. doi:10.1111/prd.12328

27. Sugimoto CR, Ahn YY, Smith E, et al. Factors affecting sex-related reporting in medical research: a cross-disciplinary bibliometric analysis. Lancet. 2019;393(10171):550-559. doi:10.1016/S01406736(18)32995-7

28. Yan W, Zheng K, Weng L, et al. Bibliometric evaluation of 20002019 publications on functional near-infrared spectroscopy. Neuroimage. 2020;220:117121. doi:10.1016/j neuroimage.2020.117121

29. Müller AM, Maher CA, Vandelanotte C, et al. Physical activity, sedentary behavior, and diet-related ehealth and mhealth research: bibliometric analysis. J Med Internet Res. 2018;20(4):e122. doi:10.2196/jmir.8954

30. Chen C. CiteSpace II: detecting and visualizing emerging trends and transient patterns in scientific literature. J Am Soc Inf Sci Technol. 2006;57(3):359-377. doi:10.1002/asi.20317

31. Chen C. Searching for intellectual turning points: progressive knowledge domain visualization. Proc Natl Acad Sci USA. 2004;101 (Suppl1):5303-5310. doi:10.1073/pnas.0307513100
32. Liang YD, Li Y, Zhao J, et al. Study of acupuncture for low back pain in recent 20 years: a bibliometric analysis via CiteSpace. J Pain Res. 2017;10:951-964. doi:10.2147/JPR.S132808

33. Hirsch JE. An index to quantify an individual's scientific research output. Proc Natl Acad Sci. 2005;102(46):16569-16572. doi:10.1073/pnas.0507655102

34. Smith MJ, Weinberger C, Bruna EM, et al. The scientific impact of nations: journal placement and citation performance. PLoS One. 2014;9(10):e109195. doi:10.1371/journal.pone.0109195

35. Chen CM. Science mapping: a systematic review of the literature. J Data Inf Sci. 2017;2(2):1-40. doi:10.1515/jdis-2017-0006

36. Murray CJ, Atkinson C, Bhalla $\mathrm{K}$, et al. The state of US health, 1990-2010: burden of diseases, injuries, and risk factors. JAMA. 2013;310(6):591-608. doi:10.1001/jama.2013.13805

37. Chou R, Qaseem A, Snow V, et al. Diagnosis and treatment of low back pain: a joint clinical practice guideline from the American College of Physicians and the American Pain Society. Ann Intern Med. 2007;147(7):478-491. doi:10.7326/0003-4819-1477-200710020-00006

38. Zhao D, Li J, Seehus C, et al. Bibliometric analysis of recent sodium channel research. Channels (Austin). 2018;12(1):311-325. doi:10.1080/19336950.2018.1511513

39. Synnestvedt MB, Chen C, Holmes JH. CiteSpace II: visualization and knowledge discovery in bibliographic databases. AMIA Annu Symp Proc. 2005;2005:724-728.

40. Pengel LH, Herbert RD, Maher CG, et al. Acute low back pain: systematic review of its prognosis. BMJ. 2003;327(7410):323. doi:10.1136/bmj.327.7410.323

41. Childs JD, Fritz JM, Flynn TW, et al. A clinical prediction rule to identify patients with low back pain most likely to benefit from spinal manipulation: a validation study. Ann Intern Med. 2004;141 (12):920-928. doi:10.7326/0003-4819-141-12-200412210-00008

42. Qaseem A, Wilt TJ, McLean RM, et al.; Clinical Guidelines Committee of the American College of Physicians. Noninvasive treatments for acute, subacute, and chronic low back pain: a clinical practice guideline from the American College of Physicians. Ann Intern Med. 2017;166(7):514-530. doi:10.7326/M16-2367.

43. Airaksinen O, Brox JI, Cedraschi C, et al. Chapter 4. European guidelines for the management of chronic nonspecific low back pain. Eur Spine J. 2006;15(Supp12):S192-S300. doi:10.1007/ s00586-006-1072-1

44. Pedersen BK, Saltin B. Exercise as medicine - evidence for prescribing exercise as therapy in 26 different chronic diseases. Scand J Med Sci Sports. 2015;25(Suppl 3):1-72. doi:10.1111/sms.12581

45. Da Costa BR, Vieira ER. Risk factors for work-related musculoskeletal disorders: a systematic review of recent longitudinal studies. $\mathrm{Am}$ $J$ Ind Med. 2010;53(3):285-323. doi:10.1002/ajim.20750

46. O'Sullivan P. Diagnosis and classification of chronic low back pain disorders: maladaptive movement and motor control impairments as underlying mechanism. Man Ther. 2005;10(4):242-255. doi:10.1016/ j.math.2005.07.001

47. Koes BW, van Tulder MW, Ostelo R, et al. Clinical guidelines for the management of low back pain in primary care: an international comparison. Spine (Phila Pa 1976). 2001;26(22):2504. doi:10.1097/ 00007632-200111150-00022

48. Pozzobon D, Nogueira LAC, Ferreira PH, et al. Return to self-reported physical activity level after an event of acute low back pain. PLoS One. 2019;14(7):e0219556. doi:10.1371/journal. pone.0219556

49. Fitzpatrick RB. Essential Science Indicators. Med Ref Serv $Q$. 2005;24(4):67-78. doi:10.1300/J115v24n04 05

50. Saragiotto BT, Maher CG, Yamato TP, et al. Motor control exercise for chronic non-specific low-back pain. Cochrane Database Syst Rev. 2016;(1):CD012004. doi:10.1002/14651858.CD012004 
51. Steffens D, Maher CG, Pereira LS, et al. Prevention of low back pain: a systematic review and meta-analysis. JAMA Intern Med. 2016;176 (2):199-208. doi:10.1001/jamainternmed.2015.7431

52. Aitken D, Buchbinder R, Jones $\mathrm{G}$, et al. Interventions to improve adherence to exercise for chronic musculoskeletal pain in adults. Aust Fam Physician. 2015;44(1-2):39-42. doi:10.1002/14651858. CD005956.pub2

53. Searle A, Spink M, Ho A, et al. Exercise interventions for the treatment of chronic low back pain: a systematic review and meta-analysis of randomised controlled trials. Clin Rehabil. 2015;29 (12):1155-1167. doi:10.1177/0269215515570379

54. Kamper SJ, Apeldoorn AT, Chiarotto A, et al. Multidisciplinary biopsychosocial rehabilitation for chronic low back pain: cochrane systematic review and meta-analysis. BMJ. 2015;350:h444. doi:10.1016/j.ijosm.2015.07.008

55. Park SM, Kim GU, Kim HJ, et al. Walking more than 90minutes/ week was associated with a lower risk of self-reported low back pain in persons over 50years of age: a cross-sectional study using the Korean National Health and Nutrition Examination Surveys. Spine J. 2019;19(5):846-852. doi:10.1016/j.spinee.2018.11.007

56. Notarnicola A, Fischetti F, Maccagnano G, et al. Daily pilates exercise or inactivity for patients with low back pain: a clinical prospective observational study. Eur J Phys Rehabil Med. 2014;50(1):59-66. doi:10.1186/1743-0003-11-10

57. Shiri R, Coggon D, Falah-Hassani K. Exercise for the prevention of low back pain: systematic review and meta-analysis of controlled trials. Am J Epidemiol. 2018;187(5):1093-1101. doi:10.1093/aje/ kwx337

58. Chatzitheodorou D, Kabitsis C, Malliou P, et al. A pilot study of the effects of high-intensity aerobic exercise versus passive interventions on pain, disability, psychological strain, and serum cortisol concentrations in people with chronic low back pain. Phys Ther. 2007;87 (3):304-312. doi:10.2522/ptj.20060080

59. Dos Santos I, Lunardi AC, de Oliveira NTB, et al. Effects of aerobic exercise on pain and disability in patients with non-specific chronic low back pain: a systematic review protocol. Syst Rev. 2019;8(1):101. doi:10.1186/s13643-019-1019-3

60. Delitto A, George SZ, Van Dillen L. Low back pain: clinical linked to the international classification of functioning, disability and health from the orthopaedic section of the American Physical Therapy Association. J Orthop Sports Phys Ther. 2012;42(4):A1-A57. doi:10.2519/jospt.2012.42.4.A1

61. Shiri R, Falah-Hassani K, Heliövaara M, et al. Risk factors for low back pain: a population-based longitudinal study. Arthritis Care Res (Hoboken). 2019;71(2):290-299. doi:10.1002/acr.23710

62. Wasser JG, Vasilopoulos T, Zdziarski LA, et al. Exercise benefits for chronic low back pain in overweight and obese individuals. PM R. 2017;9(2):181-192. doi:10.1016/j.pmrj.2016.06.019

63. Hashimoto Y, Matsudaira K, Sawada SS, et al. Association between objectively measured physical activity and body mass index with low back pain: a large-scale cross-sectional study of Japanese men. $B M C$ Public Health. 2018;18(1):341. doi:10.1186/s12889-018-5253-8
64. Yang H, Haldeman S. Behavior-related factors associated with low back pain in the US adult population. Spine (Phila Pa 1976). 2018;43 (1):28-34. doi:10.1097/BRS.0000000000001665

65. Smuck M, Kao MC, Brar N, et al. Does physical activity influence the relationship between low back pain and obesity? Spine J. 2014;14 (2):209-216. doi:10.1016/j.spinee.2013.11.010

66. Hershkovich O, Friedlander A, Gordon B, et al. Associations of body mass index and body height with low back pain in 829,791 adolescents. Am J Epidemiol. 2013;178(4):603-609. doi:10.1093/ aje/kwt019

67. Mikkonen PH, Laitinen J, Remes J, et al. Association between overweight and low back pain: a population-based prospective cohort study of adolescents. Spine. 2013;38(12):1026-1033. doi:10.1097/ BRS.0b013e3182843ac8

68. Dario AB, Loureiro ferreira M, Refshauge K, et al. Obesity does not increase the risk of chronic low back pain when genetics are considered. A prospective study of Spanish adult twins. Spine J. 2017;17 (2):282-290. doi:10.1016/j.spinee.2016.10.006

69. Vlaeyen JW, Linton SJ. Fear-avoidance and its consequences in chronic musculoskeletal pain: a state of the art. Pain. 2000;85 (3):317-332. doi:10.1016/S0304-3959(99)00242-0

70. Crombez G, Vlaeyen JW, Heuts PH, et al. Pain-related fear is more disabling than pain itself: evidence on the role of pain-related fear in chronic back pain disability. Pain. 1999;80(1):329-339. doi:10.1016/ S0304-3959(98)00229-2

71. Grotle M, Vøllestad NK, Veierød MB, et al. Fear-avoidance beliefs and distress in relation to disability in acute and chronic low back pain. Pain. 2004;112(3):343-352. doi:10.1016/j.pain.2004.09.020

72. Fujii T, Matsudaira K, Oka H. Factors associated with fear-avoidance beliefs about low back pain. J Orthop Sci. 2013;18(6):909-915. doi:10.1007/s00776-013-0448-4

73. Fujii T, Oka H, Takano $\mathrm{K}$, et al. Association between high fear-avoidance beliefs about physical activity and chronic disabling low back pain in nurses in Japan. BMC Musculoskelet Disord. 2019;20(1):572. doi:10.1186/s12891-019-2965-6

74. Kent P, Kjaer P. The efficacy of targeted interventions for modifiable psychosocial risk factors of persistent nonspecific low back pain-a systematic review. Man Ther. 2012;17(5):385-401. doi:10.1016/j. math.2012.02.008

75. Reese C, Mittag O. Psychological interventions in the rehabilitation of patients with chronic low back pain: evidence and recommendations from systematic reviews and guidelines. Int $J$ Rehabil Res. 2013;36(1):6-12. doi:10.1097/MRR.0b013e32835acfec

76. Hitt HC, McMillen RC, Thornton-Neaves T, et al. Comorbidity of obesity and pain in a general population: results from the Southern Pain Prevalence Study. J Pain. 2007;8(5):430-436. doi:10.1016/j. jpain.2006.12.003

77. Crombez G, Eccleston C, Van Damme S, et al. Fear-avoidance model of chronic pain: the next generation. Clin J Pain. 2012;28 (6):475-483. doi:10.1097/AJP.0b013e3182385392

78. Vincent HK, Omli MR, Day T, et al. Fear of movement, quality of life, and self-reported disability in obese patients with chronic lumbar pain. Pain Med. 2011;12(1):154-164. doi:10.1111/j.1526-4637
Journal of Pain Research

\section{Publish your work in this journal}

The Journal of Pain Research is an international, peer reviewed, open access, online journal that welcomes laboratory and clinical findings in the fields of pain research and the prevention and management of pain. Original research, reviews, symposium reports, hypothesis formation and commentaries are all considered for publication. The manuscript management system is completely online and includes a very quick and fair peer-review system, which is all easy to use. Visit http:// www.dovepress.com/testimonials.php to read real quotes from published authors. 